\title{
Drugs of Abuse in HIV infection and neurotoxicity
}

\author{
Melissa Hidalgo ${ }^{\dagger}$, Venkata S. R. Atluri ${ }^{\text {*t }}$ and Madhavan Nair * \\ Department of Immunology, Institute of Neurolmmune Pharmacology, Herbert Wertheim College of Medicine, Florida \\ International University, Miami, FL, USA
}

Keywords: HIV, neurocognitive disorders, nicotine, methamphetamine, cocaine, cannabinoids, opioids, alcohol

\section{Introduction}

HIV is a neurotropic virus that enters the brain right after infection. In the brain, HIV replicates in macrophages, microglia and small number of astrocytes $(4.7 \pm 2.8 \%$ in vitro and $8.2 \pm$ 3.9 in vivo) (Eugenin et al., 2011) causing inflammatory and neurotoxic host responses. Severe neurological disorders caused by HIV are collectively known as HIV-associated neurocognitive disorders (HAND). HAND is characterized by development of abnormal reduction of motor speed, concentration, and memory. HAND consists of several clinical forms ranging from asymptomatic neurocognitive impairment (ANI), minor neurocognitive disorder (MND) to the most severe HIVassociated dementia (HAD) (McArthur and Brew, 2010). HIV-encephalitis (HIVE) is the main

OPEN ACCESS

Edited by:

Akihide Ryo,

Yokohama City University, Japan

Reviewed by:

Kotaro Shirakawa,

Kyoto University Hospital, Japan Atsuhisa Ueda

Yokohama City University, Japan

${ }^{*}$ Correspondence:

Venkata S. R. Atluri, dratluri@aol.com Madhavan Nair

nairm@fiu.edu

${ }^{\dagger}$ These authors have contributed equally to this work.

Specialty section: This article was submitted to Virology, a section of the journal Frontiers in Microbiology

Received: 24 January 2015 Accepted: 03 March 2015 Published: 24 March 2015

Citation:

Hidalgo M, Atluri VSR and Nair M (2015) Drugs of Abuse in HIV infection and neurotoxicity.

Front. Microbiol. 6:217.

doi: 10.3389/fmicb.2015.00217 cause of HAND and the most common neurologic disorder of the brain in HIV-1 infection. HIV-1 exhibits extensive genetic variation worldwide and is categorized into three groups $(M, O$, and $N)$ and genetically into nine different subtypes $(\mathrm{A}-\mathrm{K})$. Of these, clades $\mathrm{B}$ and $\mathrm{C}$ represent the majority (>86\%) of circulating HIV-1 variants (Osmanov et al., 2002). While HIV-1 clade B is predominant in North America, Western Europe, and Australia; clade C is common in Southern and East Africa, India and Nepal (responsible for around half of all HIV infections). HIV-1 clade B has been reported to be more neuropathogenic than clade C (Atluri et al., 2013; Samikkannu et al., 2014). Before the worldwide use of highly antiretroviral therapy (HAART), approximately, $20-30 \%$ of individuals with advanced HIV-1 clade B infection showed symptoms of HAD (Gonzalez-Scarano and MartinGarcia, 2005; Kaul et al., 2005). Although the prevalence of HAD has decreased intensely after the introduction of HAART, $40-50 \%$ of HIV positive patients still suffer from HAND (Sacktor et al., 2001; Sacktor, 2002; McArthur, 2004; Antinori et al., 2007; Ellis et al., 2007). In developed countries, about $30 \%$ of HIV-positive individuals are intravenous drug abusers, which place them in a higher risk for HAND (Miro et al., 2003; Beyrer et al., 2010). Cocaine and marijuana are the most common drugs of abuse among HIV patients, whereas opioids are abused only by a small number of patients (Kuo et al., 2004; Cook et al., 2007; Korthuis et al., 2008). Overall, several drugs of abuse such as tobacco, stimulants, cannabinoids, opioids and alcohol are found to be consumed among HIV infected individuals, having an effect on synaptic plasticity and development found in the brain (Hauser and Knapp, 2014). Figure $\mathbf{1}$ is showing different neurotoxic mechanisms of drugs of abuse in HIV infection which may lead to the impaired neurocognitive functions.

\section{Nicotine and HIV}

Recently, in nicotine and HIV infected SK-N-MC cells, an up-regulation of HDAC2 was observed (Atluri et al., 2014). HDAC2 overexpression has been reported in depleted memory formation, synaptic plasticity and dendritic spine density (Guan et al., 2009). Nevertheless, use of nicotine in infected patients can have beneficial outcomes on neurological deficits that were HIV-1 induced (Cao et al., 2013). In nicotine injected HIV-1 transgenic rats brain regions, such 


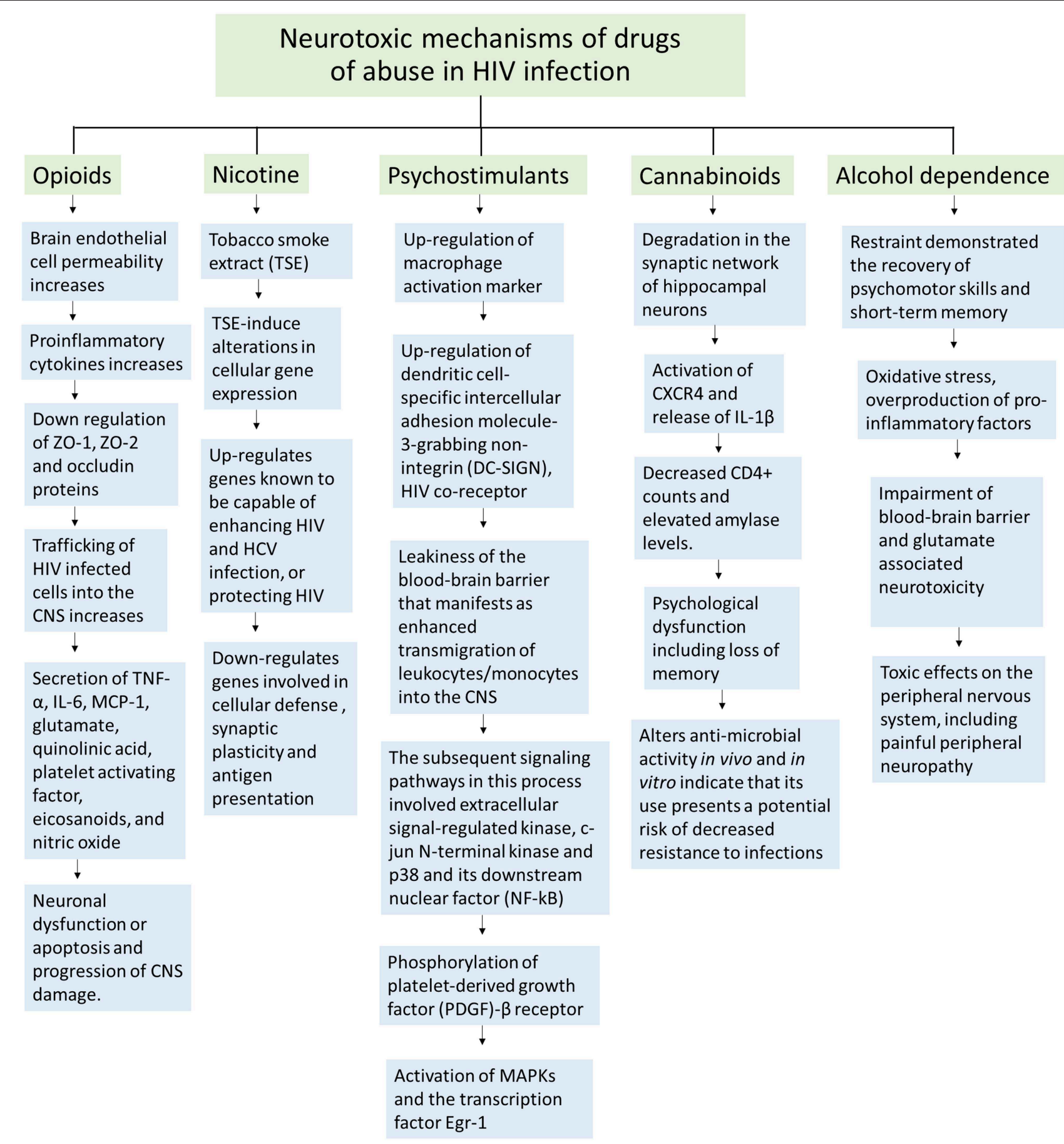

FIGURE 1 | Schematic representation of neurotoxic mechanisms of different illicit drugs of abuse in HIV infection.

as in the prefrontal cortex, Wnt $/ \beta$-catenin signaling has shown improvement by restoring the down-regulation of Axin1, Wnt5a, Wnt7 $a$ and the up-regulation of Gnaol (Cao et al., 2013). This signaling pathway plays an important role in the early development of the nervous system, in which a neuroprotective outcome in adults is established after the activation of this pathway (Nave and Trapp, 2008). These results are important since central demyelination and neurodegeneration have been observed in HIV-1 infected individuals. In the dorsal hippocampus, CREB signaling has also been restored, in which the decreased expression of calcium sensor proteins, Calm3 and Cabp1, was regulated to normal levels. This signaling pathway is significant in neuronal survival and long-term synaptic plasticity. In the dorsal striatum, nicotine has also shown to restore the function of the 
tricarboxylic acid (TCA) cycle and its related pathways, such as the down-regulation of $I d h 3 B$ and up-regulation of $N d u f s 4$ that came back to normal levels (Cao et al., 2013).

\section{Psychostimulants and HIV}

Stimulants such as cocaine indicated to be involved in upregulation of macrophage activation marker human leukocyte antigen (HLA)-DR and increased HIV replication in monocytes, and even astrocytes in vitro (Dhillon et al., 2007). Additionally, cocaine can induce HIV infection by the up-regulation of dendritic cell-specific intercellular adhesion molecule-3grabbing non-integrin (DC-SIGN), which is another HIV coreceptor (Nair et al., 2004). Cocaine can also induce monocyte transendothelial migration, expression of endothelial adhesion molecules, and disruption of intercellular junctions in the blood brain barrier (BBB) in vitro (Fiala et al., 2005). HIV patients with cocaine dependence reported to have a greater neurocognitive impairment and poorer HAART adherence compared to nondrug users (Meade et al., 2011). Dendritic varicosity formation was enhanced in primary hippocampus neurons in the presence of HIV-1 envelope glycoprotein gp120 and cocaine (Yao et al., 2009). These findings proof that cocaine intensifies HIV infection and neuronal damage.

On the other hand, methamphetamine (meth) is a neurotoxic drug that injures dopaminergic neurons and reduces dopamine as well as norepinephrine in the brain (McCann et al., 1998). Moreover, in HIV infected meth abusers, a more cognitive impairment was related to a smaller hippocampal volume (Berman et al., 2008). The expression of HIV co-receptors, CXCR4 and CCR5, and HIV replication in astrocytes were both increased in presence of meth (Nair et al., 2009). BBB dysfunction and an increase in the expression of pro-inflammatory cytokinesis were observed, which can lead to meth-neurotoxicity (Czub et al., 2001; Nath et al., 2002). Meth and gp120 cooperated to induce interleukin-6 (IL-6) and cytochrome P450 2E1 (CYP2E1) in astrocytes (Shah et al., 2013). CYP2E1 generated free electrons and reactive oxygen species (ROS) through its reaction cycle. Further, caspase-3 activity increased, leading to DNA fragmentation and apoptosis in astrocytes (Shah et al., 2013). The expression of ZO-1, claudin-3, claudin-5, and JAM-2 also decreased in combination of Meth and gp120 or Tat (Mahajan et al., 2008; Banerjee et al., 2010). Levels of matrix metalloproteinase 2 (MMP-2) and MMP-9 secretions increased in the presence of meth and Tat treatment (Conant et al., 2004). These data then proofs exacerbation of neurotoxicity in HIV and meth combination.

\section{Cannabinoids and HIV}

The consumption of cannabinoids, in HIV infected individuals was reported to modify inflammatory and neurotoxic processes. Studies on HIV gp120 treated cells demonstrated degradation in the synaptic network of hippocampal neurons (Kim et al., 2011). These occurred when activation of CXCR4, triggered cell signaling pathways and the release of IL-1 $\beta$ (Yi et al., 2004). This $\beta$-chemokine is responsible for mediation of synapse loss, which activates an ubiquitin ligase and the N-methyl-D-aspartate
(NMDA) receptor. This receptor is responsible for the control of memory function and synaptic plasticity. The synapse loss was said to be a protective mechanism rather than an agonal event, which prevents cells from being over stimulated (Kim et al., 2011).

However, the cannabinoid receptor full agonist (Win55212-2) functioned as a protector for hippocampal neurons against gp120-induced IL- $1 \beta$ production and synapse loss. This protection has been reported to be mediated by the CB2 cannabinoid receptor, not the CB1. However, in exposure to the HIV-1 protein Tat, Win55212-2 did not inhibit synaptic loss (Kim et al., 2011). It was also reported that the cannabinoid CB2 receptor agonist (AM1241) intensifies neurogenesis in vivo and reduces astrogenesis and gliogenesis in the hippocampus of GFAP/Gp120 transgenic mouse model (Avraham et al., 2014). This is an important research content in the medical field for the future treatment of neurodegenerative diseases and related disorders.

Moreover, the consumption of marijuana and its effects on cognitive function is controversial. Marijuana consumption is a common practice in HIV-infected individuals for different interests, such as recreational and medicinal purposes. However, reports are scanty on the impact of marijuana on cognitive functions in these subjects. In a cohort study, the measurement of cognitive impairment demonstrated synergistic effects of marijuana consumption in individuals with advanced HIV disease whereas minimal impact on uninfected or those at early stages of HIV infection (Cristiani et al., 2004).

\section{Opioids and HIV}

HIV viral proteins and opioid drugs are known as cofactors for HIV infection because they act in synergy, leading to a greater immunosuppression. HIV-1 Tat and morphine demonstrated a synergistic effect in the up-regulation of inflammatory cytokines and chemokines as well as a reduction in total spine density (Fitting et al., 2011). This was observed when $\mu$-opioid receptor (MOPr) interacted with glutamatergic signals that came from $\alpha-$ amino-3-hydroxy-5-methyl-4-isoxazolepropionic acid (AMPA) receptors (Liao et al., 2005). The over activation of NMDA receptor by Tat ( $\mathrm{Li}$ et al., 2008), caused an excitotoxic manifestation that inhibited ATP production and disruption in cellular energetics (Perry et al., 2005). Fitting et al. reported a novel finding on HIV-1 Tat and morphine-induced synaptodendritic injury mediated by increased intracellular sodium $([\mathrm{Na}(+)] \mathrm{i})$ and calcium $([\mathrm{Ca}(2+)] \mathrm{i})$ in dendrites (Fitting et al., 2014).

In addition, the disturbance of synaptic transmissions in dorsolateral prefrontal cortex (DLPFC) has been observed in subjects that exhibit HIV encephalitis (HIVE) or HIV-associated neurocognitive disorders (HAND). In HIVE patients, expression of preproenkephalin (PENK), an opioid neurotransmitter, was reduced and interferon regulatory factor 1 (IRF1) expression was increased (Gelman et al., 2012); these are related neuropathologically to HIVE.

\section{Alcohol Dependence and HIV Infection}

It has been reported that lifetime alcohol dependence is able to impair memory, attention and learning. However, cognitive 
dysfunctions are not all transient (Darke et al., 2000). Although restraint demonstrated the recovery of psychomotor skills and short-term memory; long-term memory injuries were observed to last up to 7 years (Brandt et al., 1983). In a comparative study between HIV-infected and uninfected individuals that had an alcohol dependence history, major cognitive impairment in HIV-infected group was observed within the domains of reaction time, auditory processing, and verbal reasoning, whereas no major impairments were observed in the other group. Thus, this showed the synergistic effects that HIV and alcohol have on the central nervous system (CNS) (Green et al., 2004).

\section{Clinical Studies on Effect of Drugs of Abuse in HIV Associated Neurocognitive Impairment}

Several studies have associated cocaine, methamphetamine and opioid use with the aggravation of the risk for neurocognitive impairment and neuronal injury in HIV infected individuals (Martin-Thormeyer and Paul, 2009; Banerjee et al., 2011; Byrd et al., 2011; Dutta and Roy, 2012). Nonetheless, a recent large cohort study found that participants with histories of substance use (alcohol, cocaine, cannabis, opiates, and methamphetamine) did not exhibit higher rates of neurocognitive or functional impairment in everyday life (Byrd et al., 2011). The majority of these individuals were not current users and less than a third reported using illicit substances within the last year. According to the authors, continuous phases of drug abstinence might be enough for a full or partial recovery from neurocognitive impairment. These results are consistent with another longitudinal study, in which a neurocognitive function improvement was observed in long-term abstinent meth users (average of 13 months) in comparison with non-abstinent meth users (Iudicello et al., 2010). These findings propose that drugs of abuse might

\section{References}

Antinori, A., Trotta, M. P., Lorenzini, P., Torti, C., Gianotti, N., Maggiolo, F., et al. (2007). Virological response to salvage therapy in HIV-infected persons carrying the reverse transcriptase K65R mutation. Antivir. Ther. 12, 1175-1183.

Atluri, V. S., Kanthikeel, S. P., Reddy, P. V., Yndart, A., and Nair, M. P. (2013). Human synaptic plasticity gene expression profile and dendritic spine density changes in HIV-infected human CNS cells: role in HIV-associated neurocognitive disorders (HAND). PLoS ONE 8:e61399. doi: 10.1371/journal.pone.0061399

Atluri, V. S., Pilakka-Kanthikeel, S., Samikkannu, T., Sagar, V., Kurapati, K. R., Saxena, S. K., et al. (2014). Vorinostat positively regulates synaptic plasticity genes expression and spine density in HIV infected neurons: role of nicotine in progression of HIV-associated neurocognitive disorder. Mol. Brain 7:37. doi: 10.1186/1756-6606-7-37

Avraham, H. K., Jiang, S., Fu, Y., Rockenstein, E., Makriyannis, A., Zvonok, A., et al. (2014). The cannabinoid CB2 receptor agonist AM1241 enhances neurogenesis in GFAP/Gp120 transgenic mice displaying deficits in neurogenesis. $\mathrm{Br}$. J. Pharmacol. 171, 468-479. doi: 10.1111/bph.12478

Banerjee, A., Strazza, M., Wigdahl, B., Pirrone, V., Meucci, O., and Nonnemacher, M. R. (2011). Role of mu-opioids as cofactors in human immunodeficiency virus type 1 disease progression and neuropathogenesis. J. Neurovirol. 17, 291-302. doi: 10.1007/s13365-011-0037-2 have a limited legacy outcome on neurocognitive injury in HIV infected individuals and that recent substance use may be more relevant to modulating HIV neuropathogenesis. Further supporting a role for drugs of abuse increasing neuroinflammation and associated neurodegeneration, HIV-encephalitis diagnosis is more frequent in HIV positive individuals who abuse drugs in comparison to HIV positive controls (Buch et al., 2012; Liu et al., 2012).

\section{Conclusions}

An understanding of the close and bidirectional relationship between cognitive impairment and HIV risk factors is essential to efficiently reduce HIV risk. Clearly, the use of drugs of abuse plays a critical role in HIV infected individuals, affecting their neurological functioning and pathogenesis of HIV. Loss of synaptic connections has been associated with HIV-1 associated dementia (HAD). However, since there are inhibitory and excitatory connections, then this synapse loss, induced by HIV1, Tat, gp120 proteins in association with drugs of abuse, is reversible. These data contribute to the improvement of neuropathological outcomes in HIV individuals by offering new insights for possible medical treatments that will target inhibitory synapses among other techniques to treat HAD, HIVE, HAND and related neurodegenerative diseases in drug abusing patients. Further studies exploring the specific effects of applying cognitive remediation approaches in HIV-specific interventions should be directed.

\section{Acknowledgments}

This work was supported by National Institute of Health Grants: 1R01MH085259, 1R01DA027049, 1R037DA025576, 1R01DA037838 and R01DA034547.

Banerjee, A., Zhang, X., Manda, K. R., Banks, W. A., and Ercal, N. (2010). HIV proteins (gp120 and Tat) and methamphetamine in oxidative stress-induced damage in the brain: potential role of the thiol antioxidant $\mathrm{N}$-acetylcysteine amide. Free Radic. Biol. Med. 48, 1388-1398. doi: 10.1016/j.freeradbiomed.2010.02.023

Berman, S., O’Neill, J., Fears, S., Bartzokis, G., and London, E. D. (2008). Abuse of amphetamines and structural abnormalities in the brain. Ann. N.Y. Acad. Sci. 1141, 195-220. doi: 10.1196/annals.1441.031

Beyrer, C., Wirtz, A. L., Baral, S., Peryskina, A., and Sifakis, F. (2010). Epidemiologic links between drug use and HIV epidemics: an international perspective. J. Acquir. Immune Defic. Syndr. 55(Suppl. 1), S10-S16. doi: 10.1097/QAI.0b013e3181f9c0c9

Brandt, J., Butters, N., Ryan, C., and Bayog, R. (1983). Cognitive loss and recovery in long-term alcohol abusers. Arch. Gen. Psychiatry 40, 435-442. doi: 10.1001/archpsyc.1983.01790040089012

Buch, S., Yao, H., Guo, M., Mori, T., Su, T.-P., and Wang, J. (2012). Cocaine and HIV-1 interplay: molecular mechanisms of action and addiction. J. Neuroimmune Pharmacol. 6, 503-515. doi: 10.1007/s11481-011-9297-0

Byrd, D. A., Fellows, R. P., Morgello, S., Franklin, D., Heaton, R. K., Deutsch, R., et al. (2011). Neurocognitive impact of substance use in HIV infection. J. Acquir. Immune Defic. Syndr. 58, 154-162. doi: 10.1097/QAI.0b013e318229ba41

Cao, J., Wang, S., Wang, J., Cui, W., Nesil, T., Vigorito, M., et al. (2013). RNA deep sequencing analysis reveals that nicotine restores impaired gene expression by 
viral proteins in the brains of HIV-1 transgenic rats. PLoS ONE 8:e68517. doi: 10.1371/journal.pone.0068517

Conant, K., St Hillaire, C., Anderson, C., Galey, D., Wang, J., and Nath, A. (2004). Human immunodeficiency virus type 1 Tat and methamphetamine affect the release and activation of matrix-degrading proteinases. J. Neurovirol. 10, 21-28. doi: $10.1080 / 13550280490261699$

Cook, J. A., Grey, D. D., Burke-Miller, J. K., Cohen, M. H., Vlahov, D., Kapadia, F., et al. (2007). Illicit drug use, depression and their association with highly active antiretroviral therapy in HIV-positive women. Drug Alcohol Depend. 89, 74-81. doi: 10.1016/j.drugalcdep.2006.12.002

Cristiani, S. A., Pukay-Martin, N. D., and Bornstein, R. A. (2004). Marijuana use and cognitive function in HIV-infected people. J. Neuropsychiatry Clin. Neurosci. 16, 330-335. doi: 10.1176/jnp.16.3.330

Czub, S., Koutsilieri, E., Sopper, S., Czub, M., Stahl-Hennig, C., Muller, J. G., et al. (2001). Enhancement of central nervous system pathology in early simian immunodeficiency virus infection by dopaminergic drugs. Acta Neuropathol. 101, 85-91. doi: 10.1007/s004010000313

Darke, S., Sims, J., McDonald, S., and Wickes, W. (2000). Cognitive impairment among methadone maintenance patients. Addiction 95, 687-695. doi: 10.1046/j.1360-0443.2000.9556874.x

Dhillon, N. K., Williams, R., Peng, F., Tsai, Y. J., Dhillon, S., Nicolay, B., et al. (2007). Cocaine-mediated enhancement of virus replication in macrophages: implications for human immunodeficiency virus-associated dementia. J. Neurovirol. 13, 483-495. doi: 10.1080/13550280701528684

Dutta, R., and Roy, S. (2012). Mechanism(s) involved in Opioid drug abuse modulation of HAND. Curr. HIV Res. 10, 469-477. doi: $10.2174 / 157016212802138805$

Ellis, R., Langford, D., and Masliah, E. (2007). HIV and antiretroviral therapy in the brain: neuronal injury and repair. Nat. Rev. Neurosci. 8, 33-44. doi: $10.1038 /$ nrn2040

Eugenin, E. A., Clements, J. E., Zink, M. C., and Berman, J. W. (2011). HIV infection of human astrocytes disrupts blood brain barrier integrity by a gap junction dependent mechanism. J. Neurosci. 31, 9456-9465. doi: 10.1523/JNEUROSCI.1460-11.2011

Fiala, M., Eshleman, A. J., Cashman, J., Lin, J., Lossinsky, A. S., Suarez, V., et al. (2005). Cocaine increases human immunodeficiency virus type 1 neuroinvasion through remodeling brain microvascular endothelial cells. J. Neurovirol. 11, 281-291. doi: 10.1080/13550280590952835

Fitting, S., Knapp, P. E., Zou, S., Marks, W. D., Bowers, M. S., Akbarali, H. I., et al. (2014). Interactive HIV-1 Tat and morphine-induced synaptodendritic injury is triggered through focal disruptions in $\mathrm{Na}(+)$ influx, mitochondrial instability, and $\mathrm{Ca}(2)(+)$ overload. J. Neurosci. 34, 12850-12864. doi: 10.1523/JNEUROSCI.5351-13.2014

Fitting, S., Xu, R., Bull, C., Buch, S. K., El-Hage, N., Nath, A., et al. (2011). Interactive comorbidity between opioid drug abuse and HIV-1 Tat. Am. J. Pathol. 177, 1397-1410. doi: 10.2353/ajpath.2010.090945

Gelman, B. B., Lisinicchia, J. G., Chen, T., Johnson, K. M., Jennings, K., Freeman, D. H. Jr., et al. (2012). Prefrontal dopaminergic and enkephalinergic synaptic accommodation in HIV-associated neurocognitive disorders and encephalitis. J. Neuroimmune Pharmacol. 7, 686-700. doi: 10.1007/s11481-0129345-4

Gonzalez-Scarano, F., and Martin-Garcia, J. (2005). The neuropathogenesis of AIDS. Nat. Rev. Immunol. 5, 69-81. doi: 10.1038/nri1527

Green, J. E., Saveanu, R. V., and Bornstein, R. A. (2004). The effect of previous alcohol abuse on cognitive function in HIV infection. Am. J. Psychiatry 161, 249-254. doi: 10.1176/appi.ajp.161.2.249

Guan, J. S., Haggarty, S. J., Giacometti, E., Dannenberg, J. H., Joseph, N., Gao, J., et al. (2009). HDAC2 negatively regulates memory formation and synaptic plasticity. Nature 459, 55-60. doi: 10.1038/nature07925

Hauser, K. F., and Knapp, P. E. (2014). Interactions of HIV and drugs of abuse: the importance of glia, neural progenitors, and host genetic factors. Int. Rev. Neurobiol. 118, 231-313. doi: 10.1016/B978-0-12-801284-0. 00009-9

Iudicello, J. E., Woods, S. P., Vigil, O., Scott, J. C., Cherner, M., Heaton, R. K., et al. (2010). Longer term improvement in neurocognitive functioning and affective distress among methamphetamine users who achieve stable abstinence. J. Clin. Exp. Neuropsychol. 32, 704-718. doi: 10.1080/13803390903 512637
Kaul, M., Zheng, J., Okamoto, S., Gendelman, H. E., and Lipton, S. A. (2005). HIV1 infection and AIDS: consequences for the central nervous system. Cell Death Differ. 12(Suppl. 1), 878-892. doi: 10.1038/s..cdd.4401623

Kim, H. J., Shin, A. H., and Thayer, S. A. (2011). Activation of cannabinoid type 2 receptors inhibits HIV-1 envelope glycoprotein gp120-induced synapse loss. Mol. Pharmacol. 80, 357-366. doi: 10.1124/mol.111.071647

Korthuis, P. T., Zephyrin, L. C., Fleishman, J. A., Saha, S., Josephs, J. S., McGrath, M. M., et al. (2008). Health-related quality of life in HIV-infected patients: the role of substance use. AIDS Patient Care STDS 22, 859-867. doi: 10.1089/apc.2008.0005

Kuo, W. H., Wilson, T. E., Weber, K. M., Madhava, V., Richardson, J., Delapenha, R., et al. (2004). Initiation of regular marijuana use among a cohort of women infected with or at risk for HIV in the Women's Interagency HIV Study (WIHS). AIDS Patient Care STDS 18, 702-713. doi: 10.1089/apc.2004.18.702

Li, W., Huang, Y., Reid, R., Steiner, J., Malpica-Llanos, T., Darden, T. A., et al. (2008). NMDA receptor activation by HIV-Tat protein is clade dependent. J. Neurosci. 28, 12190-12198. doi: 10.1523/JNEUROSCI.3019-08.2008

Liao, D., Lin, H., Law, P. Y., and Loh, H. H. (2005). Mu-opioid receptors modulate the stability of dendritic spines. Proc. Natl. Acad. Sci. U.S.A. 102, 1725-1730. doi: 10.1073/pnas.0406797102

Liu, X., Silverstein, P. S., Singh, V., Shah, A., Qureshi, N., and Kumar, A. (2012). Methamphetamine increases LPS-mediated expression of IL-8, TNF-Î \pm and IL$1 \hat{\mathrm{I}}^{2}$ in human macrophages through common signaling pathways. PLoS ONE 7:e33822. doi: 10.1371/journal.pone.0033822

Mahajan, S. D., Aalinkeel, R., Sykes, D. E., Reynolds, J. L., Bindukumar, B., Adal, A., et al. (2008). Methamphetamine alters blood brain barrier permeability via the modulation of tight junction expression: implication for HIV-1 neuropathogenesis in the context of drug abuse. Brain Res. 1203, 133-148. doi: 10.1016/j.brainres.2008.01.093

Martin-Thormeyer, E. M., and Paul, R. H. (2009). Drug abuse and hepatitis C infection as comorbid features of HIV associated neurocognitive disorder: neurocognitive and neuroimaging features. Neuropsychol. Rev. 19, 215-231. doi: 10.1007/s11065-009-9101-6

McArthur, J. C. (2004). HIV dementia: an evolving disease. J. Neuroimmunol. 157, 3-10. doi: 10.1016/j.jneuroim.2004.08.042

McArthur, J. C., and Brew, B. J. (2010). HIV-associated neurocognitive disorders: is there a hidden epidemic? AIDS 24, 1367-1370. doi: 10.1097/QAD.0b013e3283391d56

McCann, U. D., Wong, D. F., Yokoi, F., Villemagne, V., Dannals, R. F., and Ricaurte, G. A. (1998). Reduced striatal dopamine transporter density in abstinent methamphetamine and methcathinone users: evidence from positron emission tomography studies with [11C]WIN-35,428. J. Neurosci. 18, 8417-8422.

Meade, C. S., Conn, N. A., Skalski, L. M., and Safren, S. A. (2011). Neurocognitive impairment and medication adherence in HIV patients with and without cocaine dependence. J. Behav. Med. 34, 128-138. doi: 10.1007/s10865-0109293-5

Miro, J. M., Del Rio, A., and Mestres, C. A. (2003). Infective endocarditis and cardiac surgery in intravenous drug abusers and HIV-1 infected patients. Cardiol. Clin. 21, 167-184, v-vi. doi: 10.1016/S0733-8651(03)00025-0

Nair, M. P., Saiyed, Z. M., Nair, N., Gandhi, N. H., Rodriguez, J. W., Boukli, N., et al. (2009). Methamphetamine enhances HIV-1 infectivity in monocyte derived dendritic cells. J. Neuroimmune Pharmacol. 4, 129-139. doi: 10.1007/s11481008-9128-0

Nair, M. P., Schwartz, S. A., Mahajan, S. D., Tsiao, C., Chawda, R. P., Whitney, R., et al. (2004). Drug abuse and neuropathogenesis of HIV infection: role of DC-SIGN and IDO. J. Neuroimmunol. 157, 56-60. doi: 10.1016/j.jneuroim.2004.08.040

Nath, A., Hauser, K. F., Wojna, V., Booze, R. M., Maragos, W., Prendergast, M., et al. (2002). Molecular basis for interactions of HIV and drugs of abuse. J. Acquir. Immune Defic. Syndr. 31(Suppl. 2), S62-S69. doi: 10.1097/00126334200210012-00006

Nave, K. A., and Trapp, B. D. (2008). Axon-glial signaling and the glial support of axon function. Annu. Rev. Neurosci. 31, 535-561. doi: 10.1146/annurev.neuro.30.051606.094309

Osmanov, S., Pattou, C., Walker, N., Schwardlander, B., and Esparza, J. (2002). Estimated global distribution and regional spread of HIV-1 genetic subtypes in the year 2000. J. Acquir. Immune Defic. Syndr. 29, 184-190. doi: 10.1097/00042560200202010-00013 
Perry, S. W., Norman, J. P., Litzburg, A., Zhang, D., Dewhurst, S., and Gelbard, H. A. (2005). HIV-1 transactivator of transcription protein induces mitochondrial hyperpolarization and synaptic stress leading to apoptosis. J. Immunol. 174, 4333-4344. doi: 10.4049/jimmunol.174.7.4333

Sacktor, N. (2002). The epidemiology of human immunodeficiency virusassociated neurological disease in the era of highly active antiretroviral therapy. J. Neurovirol. 8(Suppl. 2), 115-121. doi: 10.1080/13550280290101094

Sacktor, N., Tarwater, P. M., Skolasky, R. L., McArthur, J. C., Selnes, O. A., Becker, J., et al. (2001). CSF antiretroviral drug penetrance and the treatment of HIV-associated psychomotor slowing. Neurology 57, 542-544. doi: 10.1212/WNL.57.3.542

Samikkannu, T., Rao, K. V., Kanthikeel, S. P., Atluri, V. S., Agudelo, M., Roy, U., et al. (2014). Immunoneuropathogenesis of HIV-1 clades B and C: role of redox expression and thiol modification. Free Radic. Biol. Med. 69, 136-144. doi: 10.1016/j.freeradbiomed.2013.12.025

Shah, A., Kumar, S., Simon, S. D., Singh, D. P., and Kumar, A. (2013). HIV gp120and methamphetamine-mediated oxidative stress induces astrocyte apoptosis via cytochrome P450 2E1. Cell Death Dis. 4, e850. doi: 10.1038/cddis.2013.374
Yao, H., Bethel-Brown, C., and Buch, S. (2009). Cocaine Exposure Results in Formation of Dendritic Varicosity in Rat Primary Hippocampal Neurons. Am. J. Infect. Dis. 5, 26-30. doi: 10.3844/ajidsp.2009.26.30

Yi, Y., Lee, C., Liu, Q. H., Freedman, B. D., and Collman, R. G. (2004). Chemokine receptor utilization and macrophage signaling by human immunodeficiency virus type 1 gp120: implications for neuropathogenesis. J. Neurovirol. 10(Suppl. 1), 91-96. doi: 10.1080/753312758

Conflict of Interest Statement: The authors declare that the research was conducted in the absence of any commercial or financial relationships that could be construed as a potential conflict of interest.

Copyright $\odot 2015$ Hidalgo, Atluri and Nair. This is an open-access article distributed under the terms of the Creative Commons Attribution License (CC BY). The use, distribution or reproduction in other forums is permitted, provided the original author(s) or licensor are credited and that the original publication in this journal is cited, in accordance with accepted academic practice. No use, distribution or reproduction is permitted which does not comply with these terms. 